\title{
DIGITAL TECHNOLOGY EMPHASIS AT WESTERN KENTUCKY UNIVERSITY
}

\author{
Jian Peng and Mark E. Cambron \\ Department of Engineering \\ Western Kentucky University \\ Bowling Green, KY 42101
}

\begin{abstract}
The Department of Engineering at Western Kentucky University (WKU) has been given the rare opportunity to develop an entirely new engineering program. Western's challenge is to create a unique undergraduate curriculum focused on the needs of current and future industrial partners.

In the 1990's, a move towards a project-based learning model was developed and is generally supported in the American engineering education undergraduate community. A primary focus of Western Kentucky University's engineering programs is to provide a project-based experience at all levels of the curriculum.

Currently, the field of Digital technology is progressing rapidly. The electrical engineering curriculum at WKU requires all students to take a minimum of three courses in this field: Digital Logic, Introduction to Industrial Automation, and Microprocessors. Students take Digital Logic in the first year. In the digital logic course students use the 7400 series TTL chips and Xilinx CPLD. Students use an Allen Bradley programmable logic controller and an Atmel AVR STK 500 Microcomputer in Introduction to Industrial Automation. Students in the microprocessors course use the Motorola HC12. Another course, EE design I, also has a strong digital component.
\end{abstract}

The results of the initial offerings, including student feedback and course assessment are included. Examples of projects tackled by the students, lessons learned by the faculty, and lists of necessary equipment are provided.

\section{Introduction}

Western Kentucky University has had an engineering technology program for more than thirty years. This program has served the need of local Kentucky industries. However, with the rapid progress in the local industries, engineering technology program can not satisfy the local industry's requirement any more. WKU decided to phase out the engineering technology program and start a brand new engineering program. In year 2000, a new engineering joint program with University of Louisville was established and first batch of engineering students were enrolled. In year 2004, we will have the first batch of graduates, and we plan to apply for an ABET accreditation visit in 2004/2005. 
From day 1, our goal has been to develop an entirely new engineering program that is more suitable to the relevant local industries and the students' learning styles. Project-based learning model was adopted for this purpose [1]. Project-based learning is gaining more support in the American undergraduate engineering education [2, 3]. Our Electrical Engineering program has strong emphasis on the implementation of design experiences. The program is committed to producing graduates who are well prepared for the start of productive, successful careers as engineering practitioners. We believe engineering practitioners are those with a foundation of basic science, mathematics, and engineering knowledge, combined with practical knowledge and hands-on experience in applying existing technology to contemporary problems.

In addition to our integrated project-based curricula, we are building a new learning environment for undergraduate engineering education. We have deliberately focused on building a new curriculum centered on the need for successful practicing engineers while not attempting to simply replicate existing engineering programs from other schools. We believe an engineering program is a living entity, not just a list of courses and syllabi organized into a catalog. We are building a faculty who will take ownership of these curricula and create the kinds of design and analytical experiences necessary to prepare students for the start of their professional careers. We recognize the progression of student experiences required to help students grow from "Learners" into "Observers" and "Assistants" and eventually "Practitioners". These are our "Roles of the Student" [1] in a project-based curriculum and this philosophy has shaped our development of the curriculum and departmental faculty promotion policy [4].

Currently, the field of digital technology is progressing rapidly. Embedded computer systems are in many diverse equipments and daily devices. "Ubiquitous computing" is a term that sums this trend. To accommodate this trend, the electrical engineering curriculum at WKU requires all students to take a minimum of three courses in this field: Digital Logic, Introduction to Industrial Automation, and Microprocessors. All freshmen are also required to take Engineering Design I, which has strong digital components.

\section{Core Courses}

The electrical engineering curriculum at WKU requires all students to take a minimum of three courses in digital field which are considered the core courses: Digital Logic, Introduction to Industrial Automation, and Microprocessors.

\section{Digital Logic}

The course introduces students to the modeling and design of digital circuits and their application to construct digital systems. Students learn to analyze a problem statement, formulate a mathematical model, and design logic networks which have the required relationship between signals at the input and output terminals. Students take this course in the first year, and this course is offered every spring. Topics covered in this course include number systems, Boolean algebra, logic gates, flip-flops, counters, and registers. To accommodate the rapid progress in the digital field, we constantly change our textbook to better suit the situation. Several different textbooks have been adopted:

Digital Fundamentals, by Thomas J. Floyd, Prentice Hall, Inc., $7^{\text {th }}$ Edition, 2000. 
Digital Systems: Principles and Applications, by Ronald J. Tocci and Neal S. Widmer. Prentice Hall, Inc., $8^{\text {th }}$ Edition, 2001.

In Spring 2004 semester, a new textbook is being used:

Logic and Computer Design Fundamentals, by M. Morris Mano and Charles R. Kime. Prentice Hall, Inc., ${ }^{\text {rd }}$ Edition, 2004.

The lab component of this course is also evolving. In the Spring 2003 offering, the lab components consisted of 7 labs and a final design project. 7400 TTL and gate array logic (GAL) chips were used. These labs are:

- Lab1: Basic Skills

- Lab2: Logic Gates

- Lab 3: Design of Alarm Circuit

- Lab 4: Programmable Logic Devices: GAL16V8

- Lab 5: Flip-Flops

- Lab 6: Counters

- Lab 7: Adders

- Final Project: Digital Clock

The lab provided a practical reinforcement of concepts presented in the class room. The students were required to fabricate a digital clock on a prototype board. The final project was challenging and rewarding experience for the students. In Spring 2004, we are going to replace some 7400 labs with Xilinx CPLD, which are donated by Xilinx through their University Donation Program [5].

\section{$\underline{\text { Introduction to Industrial Automation }}$}

Western Kentucky University has implemented a course, EE 285: Introduction to Industrial Automation, in an attempt to build a bridge between the EE and ME programs [6]. The goal is give the students a common language in this area so that multidisciplinary capstone and professional projects are more easily accomplished.

Students are assigned hardware kits containing an Allen-Bradley PLC and an Atmel AVR microcontroller, along with various sensors, switches, and other input/output devices. The students work on a range of projects to build an understanding of not only the use and integration of these devices, but also to gain an appreciation of the strengths and difficulties of using the technologies of the other discipline. Both sets of students are required to have completed a course in structured computer language. The electrical students are required to have finished their first course in both "digital circuits" and "circuits and networks". The mechanical students are required to have completed a course, "fundamentals of electrical engineering". The fundamentals of EE course introduced the mechanical students to DC and AC circuits, digital logic, and some electronics. 
This project-based course, required of both majors, is team-taught by faculty from both programs. The course is divided into three sections. The first section of the course was a 3 weeks review of digital systems. The second section was a 7 week introduction to Programmable Logic Controllers. The final section of the course was a 6 week introduction to microcontrollers.

In the Spring 2003 offering of this course, Atmel AVR assembly language and peripheral interfacing were the emphases.

- Lab 1: Review of Digital Circuits

- Lab 2: Flip Flops and State Machines

- Lab 3: Controlling A DC motor with and OP-AMP and H-Bridge Circuit

- Lab 4: PLC Experiments: Home Alarm System

- Lab 5: PLC Experiments: Home Alarm Panel

- Lab 6: PLC Experiments: Gas Pump Model

- Lab 7: PLC Experiments: PWM Prototype

- Lab 8: Introduction to Assembly Level Programming

- Lab 9: State Machines with ATMEL STK 500

- Lab 10: Multiplexing with the ATMEL STK 500

Higher-level programming languages are replacing assembly language quickly in embedded systems due to many of their advantages over the assembly language. In Spring 2004 offering, the first author adopted a new textbook, which teaches Atmel AVR programming in C language.

Embedded C Programming and the Atmel AVR, by Barnett, O'Cull, and Cox, Delmar Learning, 2003.

\section{$\underline{\text { Microcontroller }}$}

Students take this course in the third year. This is an introductory course in microprocessors. It covers CPU architecture, assembly language, stack operation, vectored interrupts, memory organization, and input/output peripheral devices based on Motorola $68 \mathrm{HC} 12$ chips. It has been offered twice by two professors, and the first author of this paper taught it in the Fall 2003 semester. Both professors adopted the same textbook:

68HC12 Microcontroller: Theory and Application, by Daniel J. Pack and Steven F. Barrett, Prentice Hall, 2002.

"Project-based learning" is the pedagogical approach we take to educate our students, and we emphasize the importance of the labs. We try to integrate lecture component and the lab component together. Many times the lecture was given in the lab room, and students were asked to perform the lab before the instructor gave the lecture. Even with the limited size of the class (both 2002 and 2003 fall semesters we had only 3 students each time due to the nature of a new EE program), the student evaluation about this approach had been positive. In Fall 2003 offering, 8 labs were performed: 
- Lab 1: Introduction to the Motorola 68HC12 Evaluation Board (EVB)

- Lab 2: HC12 Instructions

- Lab 3: Subroutine

- Lab 4: D-Bug12 Subroutines

- Lab 5: Pushbutton Switch Status: Polling vs. Interrupt

- Lab 6: LCD display

- Lab 7: TIM: Input Capture and Output Compare

- Lab 8: TIM: Pulse Accumulator

On the student evaluation forms, one student commented that the labs were too difficult. The second one wrote that early labs were too difficult and later labs better constructed. The third one gave full marks on the lab. In the future, we would like to assign a course project that can incorporate all these elements.

The first author also noticed that the students only took a 1.5 credit hours course in programming, which was taught in $\mathrm{C}$. This turned out to be not adequate. The first author had to review many programming concepts during the course, and could not cover some chapters in the textbook. To address this issue, the first author will cover C programming in EE285 course in the Spring 2004 offering.

\section{Related Courses}

Besides the core digital courses discussed above, another course, EE Design I, also has strong digital components.

\section{EE Design I}

EE design I, known as EE101, is a course offered to freshmen, most of them don't have clear idea what EE is about. This is an introductory course that focus on teaching the freshmen problem-solving techniques, teaming skills, and oral and written communication skills. It includes multiple hands-on projects [7]. The last big project is to build a mobile robot. Every student group (consist of two students) was given a material kit, which includes material for the robot's body, motors, sensors, and a BasicStamp board. Students then machined the material and constructed the robot's body, selected and mounted various sensors (bumper, sonar, infrared emitter/detector pair, etc.) on the body, soldiered wires between various components, and program the BasicStamp microcontroller. BasicStamp Visual Basic language is used due to its simplicity, because most students had not any programming experience yet. 

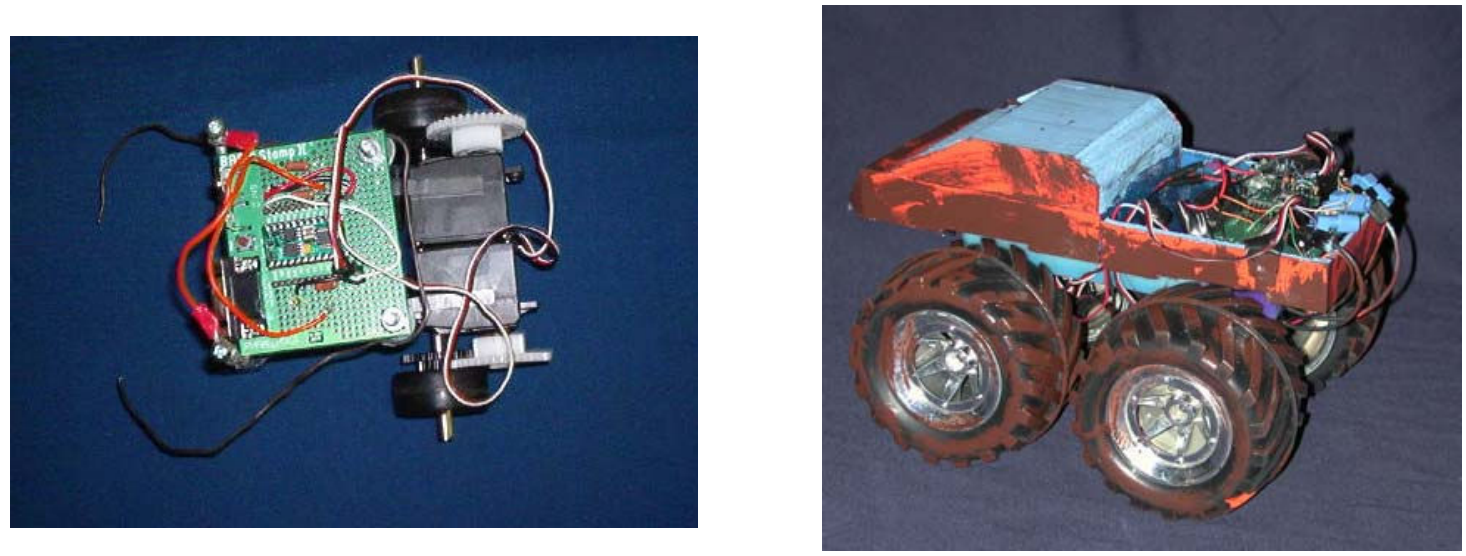

Figure 1: Two mobile robots made by students

\section{Conclusion}

The Department of Engineering at WKU has been given the rare opportunity to develop an entirely new engineering program. We want to create a unique undergraduate curriculum based on the "project-based-learning" pedagogical approach. This paper presents our effort to apply this approach in our digital technology courses. Due to the nature of a new program and small amount of students, we could not give conclusive results. However, the initial reaction from the students have been positive.

\section{Reference:}

[1] J. Lenoir and J. Russell, "The roles of the students in a project-based engineering curriculum," International Conference on Practice-Oriented Education: Transforming Higher Education, Northeastern University, Boston, MA, 2001.

[2] J. G. Harris and etc., "Journal of Engineering Round Table: Reflections on the Grinter Report," Journal of Engineering Education, vol. 81, pp. 74-94, 1994.

[3] F. L. Huband, "Engineering Education - An Alternative Approach," ASEE Prism, 1999.

[4] Promotion Criteria for the Department of Engineering, http://www.wku.edu/engineering/promote.pdf.

[5] Xilinx, http://xup.xilinx.com.

[6] M. E. Cambron and J. Lenoir, "Introcution to Industrial Automation, a Multi-Disciplinary Course at Western Kentucky University," American Society for Engineering Education Annual Conference \& Exposition, Salt Lake City, Utah, 2004.

[7] M. E. Cambron and S. Wilson, "Introducing Design to Freshmen and Sophomores at Western Kentucky University," American Society for Engineering Education Annual Conference \& Exposition, Nashville, TN, 2003. 


\section{Author Biographies}

JIAN PENG

Jian Peng is a Visiting Instructor of Electrical Engineering in the Department of Engineering at Western Kentucky University. He received his B.S. in Chemical Engineering from Zhejiang University, China, and M.S. in Electrical Engineering from Hangzhou Institute of Electrical Engineering, China. He is also working on his Ph.D. dissertation at Vanderbilt University in Nashville, TN.

MARK E. CAMBRON

Mark Cambron is an Assistant Professor of Electrical Engineering in the Department of Engineering at Western Kentucky University. He received his B.S. in Electrical Engineering from the University of Kentucky, and M.S. and $\mathrm{Ph}$.D. degrees in Electrical Engineering from Vanderbilt University in Nashville, TN. His current research interests include: engineering education, machine vision, robotics, learning systems, neural networks, and controls.

Address: 1 Big Red Way, Department of Engineering, Western Kentucky University, Bowling Green, KY 42101; email: jian.pang@wku.edu and mark.cambron@wku.edu 


\section{Electrical Engineering Curriculum}

\section{Freshman}

$\begin{array}{ll}\text { EE 175 } & \text { Freshman Seminar } \\ \text { EE 101 } & \text { EE Design I } \\ \text { MATH 126 } & \text { Calculus I } \\ \text { CHEM 120/106 } & \text { Chemistry/Lab } \\ \text { ENG 100 } & \text { Composition } \\ \text { COMM 161 } & \text { BusinessSpeaking }\end{array}$

\section{Sophomore}

EE 210

MATH 327

PHYS 260/261

ENG 200
Fall

EE Design II Circuits\&Networks I

Calculus III

Physics II/Lab

Literature

Category F Elective

$\begin{aligned} 2 & \text { CS } 245 \\ 1 & \text { EE } 180 \\ 4.5 & \text { MATH 227 } \\ 4 & \text { PHYS 250/251 } \\ 3 & \text { HIST 119/120 } \\ 3 & \\ 17.5 & \end{aligned}$

Spring

Intro to Programming Lang $\quad 1.5$

Digital Circuits

Calculus II

Physics 1/lab

Western Civilization

Category F Elective
4.5

4

3

1

\section{Spring}

Circuits\&Networks II 3

Intro to Electronics 4

Intro to Ind. Automation 2

Diff Equations 3

Economics 3

Statics 3

\section{$\underline{\text { Junior }}$}

EE 330

EE 380

MATH 350

ME 362

STAT 301

Fall

Intro to Power Systems Microprocessors Adv Engineering Math Thermal/Fluid Sciences Applied Statistics
MATH 331

ECON 202

EM 221 (UK)

$\begin{aligned} 4 & \text { EE } 300 \\ 4 & \text { EE } 420 \text { (UofL) } \\ 3 & \\ 4 & \\ 3 & \\ & \text { ENG } 300 \\ \mathbf{1 8} & \end{aligned}$

18

\section{Spring}

EE Design III 1

Signals\&Linear Sys 3

Category C Elective 3

Foreign Language 3

Category B Elective 3

Composition 3

\section{Senior}

EE 400

EE 460

EE 473(UofL)

(UofL)

Fall

EE Design IV

Cont.Control Systems

Intro to EM Fields

EE Senior Elective I

Category B Elective

\author{
EE 401 \\ EE 462 \\ EE 471 \\ EE 490
}

EE 450/451(UofL)

EE 470/475(UofL) 15
4 EE 430

4 EE 461

\section{Spring}

Capstone Design

Digital Signal Proc

EE Senior Elective II

Communications

Category E Elective

TOTAL

136.5

\section{EE Senior Elective I}

EE 410/411(UofL) Computer Design EE 421/422(UofL) Active Network Design I

\section{EE Senior Elective II}

Power Systems II 3

Discrete Control Sys 3

Special Topics in Control 3

Communications App

Introduction to Robotics 3 